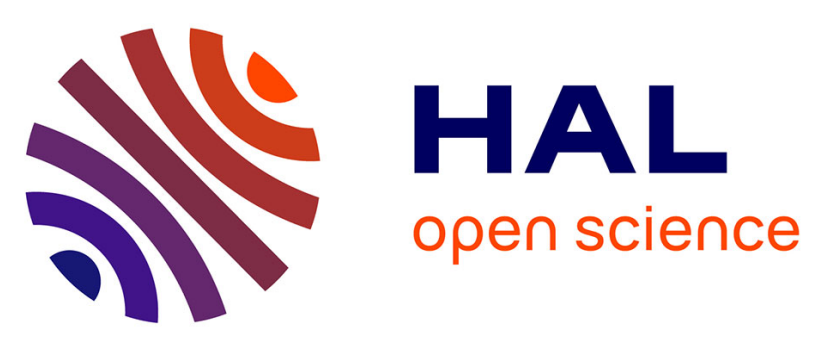

\title{
Preparation of phosphine-functionalized polystyrene stars by metal catalyzed controlled radical copolymerization and their application to hydroformylation catalysis
}

Andrés Fernando Cardozo Perez, E. Manoury, Carine Julcour-Lebigue, Jean-François Blanco, Henri Delmas, Florence Gayet, Rinaldo Poli

\section{To cite this version:}

Andrés Fernando Cardozo Perez, E. Manoury, Carine Julcour-Lebigue, Jean-François Blanco, Henri Delmas, et al.. Preparation of phosphine-functionalized polystyrene stars by metal catalyzed controlled radical copolymerization and their application to hydroformylation catalysis. Dalton Transactions, 2013, 42 (25), pp.9148-9156. 10.1039/c3dt33082f . hal-00993528

\section{HAL Id: hal-00993528 \\ https://hal.science/hal-00993528}

Submitted on 2 Mar 2021

HAL is a multi-disciplinary open access archive for the deposit and dissemination of scientific research documents, whether they are published or not. The documents may come from teaching and research institutions in France or abroad, or from public or private research centers.
L'archive ouverte pluridisciplinaire HAL, est destinée au dépôt et à la diffusion de documents scientifiques de niveau recherche, publiés ou non, émanant des établissements d'enseignement et de recherche français ou étrangers, des laboratoires publics ou privés. 


\title{
Preparation of Phosphine-Functionalized Polystyrene Stars by Metal Catalyzed Controlled Radical Copolymerization and Their Application to Hydroformylation Catalysis
}

\author{
Andrés F. Cardozo, ${ }^{a, b, c}$ Eric Manoury ${ }^{a, c}$, Carine Julcour ${ }^{b, c}$, Jean-François Blanco ${ }^{b, c}$, Henri Delmas ${ }^{b, c}$, \\ ${ }_{5}$ Florence Gayet, ${ }^{a, c}$ Rinaldo Poli ${ }^{* a, c, d}$
}

\author{
Received (in $X X X, X X X)$ Xth $X X X X X X X X X 20 X X$, Accepted Xth $X X X X X X X X X 20 X X$ \\ DOI: 10.1039/b000000x
}

Well defined star copolymers have been prepared by copper-catalyzed atom transfer radical copolymerization of styrene and styryldiphenylphosphine starting from a modified Boltorn ${ }^{\mathrm{TM}} \mathrm{H} 30$

10 multifunctional initiator. These polymers and an analogue obtained by debromination of the arm ends with $n \mathrm{Bu}_{3} \mathrm{SnH}$ have been used in combination with $\left[\mathrm{Rh}(\mathrm{acac})(\mathrm{CO})_{2}\right]$ for the homogeneous phase hydroformylation of 1-octene.

\section{Introduction}

Polymer science and the desire to fabricate advanced materials 15 with specific functions have made a giant step forward with the development of controlled radical polymerization techniques that combine functionality tolerance with precise control of architecture, topology, composition, molecular weight, mole fraction and location of specific functional groups. ${ }^{1-6} \mathrm{~A}$ 20 particularly successful protocol for controlled radical polymerization is Atom Transfer Radical Polymerization (ATRP). ${ }^{7,8}$ This is a metal-catalyzed process whereby multiple controlled insertions of monomers (M) into the halogen-capped chain end occur by reversible activation of the dormant chain $\left(\mathrm{P}_{\mathrm{n}}-\right.$

${ }_{25} \mathrm{X}$ ). It involves a halogen atom transfer process to the catalyst, a complex of a transition metal Mt supported by a given coordination sphere $\mathrm{L}\left(\mathrm{Mt}^{\mathrm{x}} / \mathrm{L}\right)$ that changes its formal oxidation state from $\mathrm{x}$ to $\mathrm{x}+1$ during the activation process, and deactivation by the reverse process (Scheme 1). ${ }^{4}, 5$ The position of 30 the ATRP equilibrium is in great favour of the dormant species over the active radicals, thereby greatly reducing the incidence of bimolecular terminations.

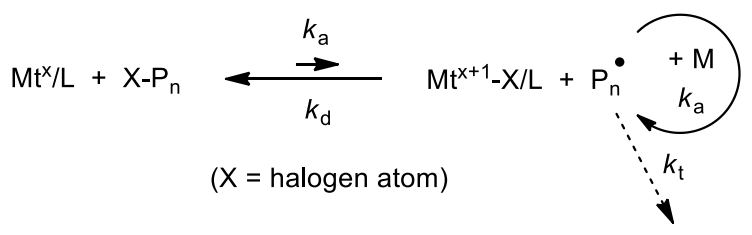

bimolecular terminations

Scheme 1. Mechanism of the ATRP process.

35 Phosphines have so far received little attention as functional groups in the controlled radical polymerization approach, in contrast with the wide interest on phosphine functionalized polymers for catalytic applications. ${ }^{9}, 10$ For instance, rhodium catalysts anchored on polymer-grafted phosphine ligands were 40 first described by Manassen ${ }^{11}$ and then developed in the 70's by Grubbs, ${ }^{12,} 13$ Čapka $^{14}$ and Pittman ${ }^{15}$ as hydrogenation, hydrosilylation and hydroformylation catalysts. Many other polymer-supported phosphine ligands have since been reported, mostly containing modified triphenylphosphine. ${ }^{9}$, 16-20 The 45 strategies used to obtain polymeric ligands can be divided into two families, the first one involving incorporation of the phosphine function by chemical modification of a pre-existing phosphine-free polymer ${ }^{16,21,22}$ and the second one involving the use of a phosphine-containing comonomers during the polymer50 ization. Notably, both linear and cross-linked triphenylphosphinecontaining polystyrenes have been obtained by copolymerization of 4-diphenylphosphinostyrene (or styryldiphenylphosphine, SDPP) and regular styrene (S) by anionic or free radical methods, possibly in the presence of $p$-divinylbenzene or 1,4-bis(455 vinylphenoxy)-butane as a cross-linking comonomer. These polymers are characterized, however, by broad molecular weight distributions and uncontrolled architectures..$^{23,24}$

Living/controlled polymerization techniques allow exerting control over these parameters but examples involving phosphine 60 containing monomers are limited. The anionic living polymerization of SDPP has provided homopolymers with narrow MW distribution, subsequently extended into diblock copolymer structures by polymerization of regular styrene. ${ }^{25}$ Terashima, Sawamoto et al. have demonstrated the power of ATRP with a ${ }_{65}$ ruthenium catalyst to produce polymers incorporating SDPP. More specifically, core-shell polymers with the phosphine functions confined in the cross-linked nanogel core were produced starting from a halogen-terminated polyacrylate macroinitiator in the presence of SDPP and a cross-linker 70 (ethylene glycol dimethyl dimethacrylate) as comonomers. ${ }^{26-28}$ These polymers have subsequently been used as macroligands to catalyze a variety of reactions. ${ }^{29-31}$

In our own laboratory, we wish to develop macroligands where 
the phosphine functions are contained on flexible linear arms rather than in a cross-linked core, thereby being potentially more accessible to substrates and reagents in catalysis. We have recently reported that the copper-catalyzed atom transfer radical 5 copolymerization of S and SDPP yields well controlled linear polymers when the amount of SDPP in the feed is up to $25 \% .{ }^{32} \mathrm{In}$ the present contribution, we extend this approach to the synthesis of well-defined phosphine-functionalized polystyrene stars. The potential of the resulting macroligands in catalysis is shown using 10 the hydroformylation of 1 -octene as a benchmark reaction.

\section{Experimental Section}

\section{General}

All glassware was dried at $125^{\circ} \mathrm{C}$ overnight. The polymerization reactions were carried out under argon in round 15 bottom Schlenk tubes connected to three-way stopcocks. All solvents (toluene, 99.7\%, Aldrich; anisole, 99.0\%, Fluka; dichloromethane, $>99.5 \%$, Aldrich; and THF, >99.9\%, Aldrich) were dried using conventional methods and then distilled under an argon atmosphere prior to use. All the purification operations 20 concerning the SDPP-containing polymers were equally conducted under argon.

Styrene (99\%) and divinylbenzene (80\%) (Sigma-Aldrich) were dried on $\mathrm{CaH}_{2}$ (99\%, Aldrich), then distilled under reduced pressure and kept under an inert atmosphere at $-25^{\circ} \mathrm{C}$ prior to use.

${ }_{25}$ The deuterated solvents for the NMR analyses were purchased from Eurisotop. 4-Styryldiphenylphosphine (97\%, Aldrich), $\mathrm{PPh}_{3}$ (99\%, Aldrich), CuBr (99.999\%, Aldrich), $\mathrm{CuBr}_{2}$ (99.0\%, Fluka), $\mathrm{CuCl}$ (99.999\%, Aldrich), $\mathrm{K}_{2} \mathrm{CO}_{3}$ (99\%, Aldrich), tris(2pyridylmethyl)amine (97\%, Aldrich), AIBN (> 98\%, ACROS), 30 [Rh(acac)(CO) 2$]$ (99\%, Alfa Aesar), 4-(dimethylamino)pyridine (99\%, Fluka), pentamethyldiethylenetriamine (99\%, Aldrich), 1bromo ehylbenzene (97\%, Aldrich), methyl 2-bromopropionate (99,0\%, Fluka), ethyl 2-bromoisobutyrate (98\%, Aldrich), triethylamine (96\%, Aldrich), 2-bromoisobutyroyl bromide $35\left(98 \%\right.$, Aldrich), $n \mathrm{Bu}_{3} \mathrm{SnH}(97 \%, \mathrm{ACROS})$, tin bis(2ethylhexanoate) (96\%, Alfa Aesar), methanol (98\%, Aldrich), hexane (>95\%, Aldrich), 1-octene (99+\%, ACROS), $n$-nonanal (> 97\%, Alfa Aesar) and dodecane (99\%, Aldrich) were used as received. Boltorn ${ }^{\mathrm{TM}} \mathrm{H} 30$ was dried under vacuum for $24 \mathrm{~h}$ at 40 room temperature and analyzed by ${ }^{1} \mathrm{H}$ NMR according to established protocols, ${ }^{33-35}$ confirming the specifications provided by the commercial source (Perstorp Chemicals; $M_{\mathrm{n}}=3600 \mathrm{~g} / \mathrm{mol}$, $\mathrm{NoH}=32$ ). $\quad N, N, N{ }^{\prime}, N$, $N$ ', $N$ "'-Hexamethyltris(2-aminoethyl)amine (Me6TREN) was prepared according to a literature 45 protocol. ${ }^{36}$ The macroinitiator $\left(\mathrm{CH}_{3}\right)_{2} \mathrm{C}(\mathrm{COOEt})-\left(\mathrm{S}_{\mathrm{x}}-c o-\mathrm{SDPP}_{\mathrm{y}}\right)-$ $\mathrm{Br}\left(\mathrm{x} \sim 40, \mathrm{y} \sim 12 ; \mathrm{M}_{\mathrm{n}, \mathrm{SEC}}=7520 \mathrm{~g} / \mathrm{mol} ; \mathrm{D}=1.38\right)$ was prepared as described in our previous contribution. ${ }^{32}$ Carbon monoxide and dihydrogen were obtained from Linde Gas. Syngas was prepared by introducing equimolar amounts of $\mathrm{CO}$ and $\mathrm{H}_{2}$ into a monitored 50 gas reservoir feeding the autoclave reactor at constant pressure.

\section{Instrumentation.}

The ${ }^{1} \mathrm{H}$ NMR spectra were recorded at $25.0{ }^{\circ} \mathrm{C}$ on Bruker Avance 300 (5 mm TXO or QNP probes) or Bruker Avance 400 (5 mm Atma BBFO probe) spectrometers operating at 300 and ${ }_{55} 400 \mathrm{MHz}$, respectively. The chemical shifts were calculated relative to the residual protonated solvent peaks as internal standards and reported in ppm with positive values upfield from $\mathrm{SiMe}_{4}$. The ${ }^{31} \mathrm{P}\left\{{ }^{1} \mathrm{H}\right\}$ NMR spectra were obtained at $25.0^{\circ} \mathrm{C}$ on a Bruker Avance 300 spectrometer operating at $121.5 \mathrm{MHz}$ and the ${ }_{60}$ chemical shifts are given in ppm relative to the signal of a $85 \%$ $\mathrm{H}_{3} \mathrm{PO}_{4}$ solution in $\mathrm{D}_{2} \mathrm{O}$, which was used as external standard. The SDPP conversion during the polymerization was followed by ${ }^{31} \mathrm{P}\left\{{ }^{1} \mathrm{H}\right\}$ NMR using a $40 \mathrm{~s}$ relaxation delay to insure the complete recovery of the magnetization vector between 65 consecutive scans and the relative areas of the free and polymerized SDPP resonances were quantified by deconvolution of the signal with help of the MestRe-C program using Lorentzian lineshapes. The amount of phosphorus in the purified polymer was measured by integration of the ${ }^{31} \mathrm{P}\left\{{ }^{1} \mathrm{H}\right\}$ NMR 70 resonance using a $50 \mathrm{~s}$ relaxation delay between pulses, against a known amount of $\mathrm{Ph}_{2} \mathrm{EtP}=\mathrm{O}$ as internal standard.

The size exclusion chromatographic (SEC) analyses were carried out at $35^{\circ} \mathrm{C}$ on an instrument equipped with a $5 \mu \mathrm{m}$ gel PL pre-column $(50 \times 7.5 \mathrm{~mm})$ and a $5 \mu \mathrm{m}$ mixed gel PL-D separation 75 column $(300 \times 7,5 \mathrm{~mm})$ from Polymer Laboratories, using THF (1 $\mathrm{mL} / \mathrm{min}$ ) pre-filtered through $200 \mathrm{~nm}$ membranes as mobile phase. The samples were prepared by dissolution in THF at concentrations of $4 \mathrm{mg} / \mathrm{mL}$, then immersed in an ultrasound bath for 1-2 min, followed by standing for at least $4 \mathrm{~h}$ for the linear 80 polymers ( $24 \mathrm{~h}$ for the star polymers) and filtration through 200 $\mathrm{nm}$ Teflon filters. Molar masses were measured with a multiangle light scattering detector (MALLS; minidawn Tristar Wyatt Technology Corporation), coupled to a differential refractometer (RI2000 Sopares). An operating protocol of total recovery of the ${ }_{85}$ injected mass was employed for the variable composition copolymers, allowing the simultaneous determination of the $\mathrm{dn} / \mathrm{dc}$ parameter. This method gave a $\mathrm{dn} / \mathrm{dc}$ value in agreement with the literature $(0.184)$ for the PS homopolymer. ${ }^{37}$ The SEC traces of the star polymers prepared by the convergent route were 90 deconvoluted as the sum of two Gaussian functions.

The gas chromatographic analyses were carried out on a Thermo Fisher Trace GC 2000 chromatograph equipped with a CB-CP WAX 52 capillary column (25 m x 0,25 mm; $0.2 \mu \mathrm{m}$ film thickness) and a flame ionization detector, using helium as carrier 95 gas.

Dynamic light scattering measurements were recorded at $25^{\circ} \mathrm{C}$ on a Malvern Instruments Nano-ZS Zetasizer for the cross-linked polymers using toluene solutions at concentrations of ca. 4 $\mathrm{mg} / \mathrm{mL}$. The dissolution was accomplished with help of an 100 ultrasound bath for $1 \mathrm{~min}$, followed by standing for $24 \mathrm{~h}$ and filtration through $450 \mathrm{~nm}$ filters. The hydrodynamic radius was obtained from the measured diffusion coefficient through the Stokes-Einstein equation.

\section{Convergent preparation of poly(S-co-SDPP) stars.}

\section{5 (a) ATRP conditions}

In a Schlenk tube equipped with a magnetic stirrer bar was prepared a solution of $\mathrm{CuBr}(22 \mathrm{mg}, 0.15 \mathrm{mmol}), \mathrm{CuBr}_{2}(4 \mathrm{mg}$, $0.02 \mathrm{mmol})$ and PMDETA $(40 \mu \mathrm{L}, 0.17 \mathrm{mmol})$ in toluene $(5 \mathrm{~mL})$. This was then mixed with a separate solution containing the ${ }_{110}\left(\mathrm{CH}_{3}\right)_{2} \mathrm{C}(\mathrm{COOEt})-\left(\mathrm{S}_{40}-\mathrm{co}-\mathrm{SDPP}{ }_{12}\right)-\mathrm{Br}$ macroinitiator $(0.574 \mathrm{~g}$, $0.076 \mathrm{mmol})$ and DVB $(0.3 \mathrm{~mL}, 1.7 \mathrm{mmol})$ in $4 \mathrm{~mL}$ of toluene. The mixture was then immersed into an oil bath thermostated at $90^{\circ} \mathrm{C}$ for $60 \mathrm{~h}$, then cooled to room temperature, diluted with $50 \mathrm{~mL}$ of toluene and filtered through an activated neutral alumina 
column. The polymer was precipitated by addition of cold hexane $(400 \mathrm{~mL})$ and the mother liquor was removed by filter-cannula. The polymer was dried under vacuum until complete removal of the residual solvent (ca. 2 days) to yield a white powder $(0.47 \mathrm{~g}$, ${ }_{5} 64 \%$ yield $) . M_{n, S E C}=130600 \mathrm{~g} / \mathrm{mol}(\mathrm{dn} / \mathrm{dc}=0.117), \mathrm{Ð}=1.52$. Cross-linking yield $=41 \%$.

Additional experiments carried out with a DVB/styrene mixture, or using $\mathrm{CuCl}$ in place of $\mathrm{CuBr}$, or other macroinitiators having shorter or longer chains yielded lower cross-linking 10 yields. Experiments carried out with EGDMA as cross-linker yielded a macrogel.

\section{(b) ARGET-ATRP conditions}

In a Schlenk tube equipped with a magnetic stirrer bar was prepared a solution of $\mathrm{CuBr}_{2}(0.5 \mathrm{mg}, 0,002 \mathrm{mmol})$, TPMA (6 $15 \mathrm{mg}, 0.02 \mathrm{mmol})$ and DVB $(210 \mu \mathrm{L}, 1.2 \mathrm{mmol})$ in toluene $(2 \mathrm{~mL})$. This was then mixed with a separate solution containing the $\left(\mathrm{CH}_{3}\right)_{2} \mathrm{C}(\mathrm{COOEt})-\left(\mathrm{S}_{40}-\mathrm{co}-\mathrm{SDPP}{ }_{12}\right)-\mathrm{Br}$ macroinitiator $(0.625 \mathrm{~g}$, $0.08 \mathrm{mmol})$ in $3 \mathrm{~mL}$ of toluene. A solution of tin bis(2ethylhexanoate) $(11 \mu \mathrm{L}, 14 \mathrm{mg}, 0.032 \mathrm{mmol})$ in toluene $(1 \mathrm{~mL})$

20 was prepared separately. A $70 \mu \mathrm{L}$ sample of this solution was added to the mixture before immersion into an oil bath thermostated at $90^{\circ} \mathrm{C}$. Additional aliquots of the tin reagent solution were added at later times $(120 \mu \mathrm{L}$ after $1 \mathrm{~h}, 310 \mu \mathrm{L}$ after $2 \mathrm{~h} 30^{\prime}$ and $500 \mu \mathrm{L}$ after $5 \mathrm{~h}$ ). After a total of $64 \mathrm{~h}$, the reaction 25 was stopped by cooling to room temperature and the polymer was recovered and dried by the same procedure described above in part (a) to yield a white powder $(0.205 \mathrm{~g}, 25 \%$ yield $) . \mathrm{M}_{\mathrm{n}, \mathrm{SEC}}=$ $1.04 \cdot 10^{6} \mathrm{~g} / \mathrm{mol}(\mathrm{dn} / \mathrm{dc}=0.028), \mathrm{Ð}=1 ; 32$. Cross-linking yield $=$ $81 \%$.

\section{${ }_{30}$ Divergent preparation of poly(S-co-SDPP) stars.}

\section{(a) Preparation of the $\mathrm{H3OBr}$ macroinitiator}

This procedure follows a protocol that was previously described for a closely related multifunctional microgel $\left(\right.$ Boltorn $\left.^{\mathrm{TM}} \mathrm{H} 40\right){ }^{38}$ In a Schlenk tube was prepared a solution of ${ }_{35}$ Boltorn $^{\mathrm{TM}} \mathrm{H} 30$ (2.25 g, $\left.0.625 \mathrm{mmol}\right)$ in THF (70 mL). After stirring overnight to insure complete dissolution, a solution of 4(dimethylamino)pyridine (4.85 g, $39.3 \mathrm{mmol}$ ) and $\mathrm{Et}_{3} \mathrm{~N}(3.52 \mathrm{~mL}$, $25.0 \mathrm{mmol})$ in THF (20 mL) was added. The reaction vessel was equipped with a dropping funnel and placed in an ice bath. A 40 solution of 2-bromoisobutyroyl bromide $(\sim 10 \mathrm{~mL}, 75.0 \mathrm{mmol})$ in $10 \mathrm{~mL}$ of THF was placed in the dropping funnel and then added dropwise over 45 min to the Boltorn ${ }^{\mathrm{TM}} \mathrm{H} 30$ solution. After the end of the addition, the reaction mixture was stirred for $2 \mathrm{~h}$ in the ice bath and then for additional $96 \mathrm{~h}$ at room temperature. The 45 precipitated salts were filtered off and the solvent was partially evaporated to ca. $20 \mathrm{~mL}$ under reduced pressure. The functionalized Boltorn ${ }^{\mathrm{TM}}$ product $(\mathrm{H} 30 \mathrm{Br})$ was precipitated by adding the mixture to $150 \mathrm{~mL}$ of cold methanol. The viscous coagulated product was washed three times with methanol, letting 50 the mixture settle overnight each time. The viscous material was dried under vacuum at $35^{\circ} \mathrm{C}$ for 3 days, yielding the product in the form of an expanded foam, which turned into a viscous resin after a few days $(1.85 \mathrm{~g}, 35 \%$ yield $) . \mathrm{M}_{\mathrm{n}, \mathrm{SEC}}=17800 \mathrm{~g} / \mathrm{mol} ; \mathrm{dn} / \mathrm{dc}$ $=0.068 ; Đ=1.46$. The ${ }^{1} \mathrm{H}$ NMR of the product confirmed the

${ }_{55}$ complete esterification of the Boltorn ${ }^{\mathrm{TM}} \mathrm{OH}$ groups (see supplemental Figure S1).

(b) Preparation of the poly(S-co-SDPP) stars from the $\mathrm{H30Br}$ core
Only the preparation of the B-3 product will be described in ${ }_{60}$ detail. In a Schlenk tube, $\mathrm{CuBr}(258 \mathrm{mg}, 1.76 \mathrm{mmol}),(56 \mathrm{mg}$, $0.25 \mathrm{mmol})$, TPMA (597 mg, $2.01 \mathrm{mmol})$ and anisole $(4 \mathrm{~mL})$ were added to styrene $(24 \mathrm{~mL}, 201.5 \mathrm{mmol})$. After stirring for 5 min at room temperature, a solution containing the $\mathrm{H} 30 \mathrm{Br}$ macroinitiator $(527 \mathrm{mg}, 0.063 \mathrm{mmol})$ and SDPP (11.62 g, 40.3 $65 \mathrm{mmol})$ in toluene $(33 \mathrm{~mL})$ was added to reactor through a Teflon cannula. The reactor was then immersed into a preheated thermostatic oil bath at $80^{\circ} \mathrm{C}$. Samples were periodically withdrawn with an argon purged syringe, diluted with toluene and filtered through an activated neutral alumina column. Three 70 separate fractions of each sample were used respectively for the gas chromatographic determination of the styrene conversion, for the ${ }^{31} \mathrm{P}$ NMR analysis of the SDPP conversion and for the polymer analysis by SEC. The reaction was stopped after $29.5 \mathrm{~h}$ and the mixture was diluted with $15 \mathrm{~mL}$ of toluene and filtered 75 through an activated neutral alumina column. The polymer was precipitated in $400 \mathrm{~mL}$ of cold hexane and separated from the mother liquor by filtration through a teflon filter cannula, then dried under vacuum (ca. 3 days) to yield a white powder $(1.25 \mathrm{~g}$, $14 \%$ yield $) . M_{n, S E C}=490600 \mathrm{~g} / \mathrm{mol}(\mathrm{dn} / \mathrm{dc}=0.059), Ð=1.13$.

80 The same reaction was repeated to produce the following polymers (the reaction conditions and the amount of reagents were the same unless otherwise stated):

B-1. Reaction time $=25.5 \mathrm{~h} ; 1.7 \mathrm{~g}(15 \%$ yield $) . \mathrm{M}_{\mathrm{n}, \mathrm{SEC}}=$ $387200 \mathrm{~g} / \mathrm{mol}(\mathrm{dn} / \mathrm{dc}=0,067), Ð=1,10 . \mathrm{DH}^{\mathrm{DLS}}=94.2 \mathrm{~nm}$ in 85 toluene.

B-2. Reaction time $=24.5 \mathrm{~h}, \mathrm{CuBr}(86 \mathrm{mg}, 0.59 \mathrm{mmol}), \mathrm{CuBr}_{2}$ (19 mg, $0.08 \mathrm{mmol}$ ), SDPP (1.937 g, $6.73 \mathrm{mmol})$, TPMA (199 $\mathrm{mg}, 0.67 \mathrm{mmol})$, styrene $(8.0 \mathrm{~mL}, 67.3 \mathrm{mmol})$, anisole $(1.0 \mathrm{~mL})$, $\mathrm{H} 30 \mathrm{Br}(176 \mathrm{mg}, 0.021 \mathrm{mmol})$ in $11 \mathrm{~mL}$ of toluene. $5.7 \mathrm{~g}(17 \%$ 90 yield $) . \mathrm{Mn}=235800 \mathrm{~g} / \mathrm{mol}(\mathrm{dn} / \mathrm{dc}=0.081), \mathrm{Ð}=1.43$.

\section{Dehalogenation of polymer B-3}

In a Schlenk tube equipped with a magnetic stirrer bar was prepared a solution of B-3 $(600 \mathrm{mg})$ and $n \mathrm{Bu} 3 \mathrm{SnH}(0.11 \mathrm{~mL}, 0.39$ $\mathrm{mmol}$ ) in $15 \mathrm{~mL}$ of toluene. After homogeneization, AIBN (1 mg, $950.007 \mathrm{mmol}$ ) was added and the reaction vessel was immersed into a preheated thermostatic oil bath at $60^{\circ} \mathrm{C}$. After $26 \mathrm{~h}$ of reaction and cooling, the polymer was recovered by precipitation in $300 \mathrm{~mL}$ of cold hexane. The polymer $(556 \mathrm{mg})$ was thus recovered after filtration and vacuum drying at $50^{\circ} \mathrm{C}$ for $24 \mathrm{~h}$. $100 \mathrm{M}_{\mathrm{n}, \mathrm{SEC}}=465800 \mathrm{~g} / \mathrm{mol}(\mathrm{dn} / \mathrm{dc}=0.083), \mathrm{D}=1.35, \mathrm{D}_{\mathrm{H}}{ }^{\mathrm{DLS}}=21 \mathrm{~nm}$ in toluene.

\section{1-octene hydroformylation}

The $\mathrm{Rh}(\mathrm{CO})_{2}(\mathrm{acac})$ precatalyst $(53.2 \mathrm{mg}, 0.2 \mathrm{mmol})$ and the desired quantity of ligand ( $\mathrm{PPh}_{3}$ or functionalized polymer) were 105 introduced into a Schlenk tube. Then, a separate mixture containing 1-octene (16 mL, $102 \mathrm{mmol})$ dodecane (inert reference, $2 \mathrm{~mL}$ ) and toluene $(84 \mathrm{~mL})$ was added through a teflon cannula and the resulting mixture was stirred for $20 \mathrm{~min}$. It was then transferred into a Hastelloy C276 autoclave equipped with a 110 gas inducing stirrer. A first sample was withdrawn, then the system was purged three times with 15 bar of dinitrogen, then four times with 15 bar of syngas. The reactor was subsequently heated under low syngas pressure ( 2 bar) and slow stirring speed (140 rpm, well under self gas induction) to hinder significant gas 115 dissolution and the start of the reaction. When the desired 
reaction temperature $\left(90^{\circ} \mathrm{C}\right)$ was achieved, stirring was stopped and the autoclave was pressurized and constantly fed with syngas at the desired pressure (20 bar). A sample was withdrawn to evaluate the amount of products formed during the heating 5 procedure. Then, the data acquisition was started and the stirring speed was set to $1200 \mathrm{rpm}$. Both temperature and pressure of the reactor and the gas ballast were recorded on-line on a computer at a rate of $1 \mathrm{~Hz}$. The instantaneous reaction rate was measured from the syngas consumption. Samples were withdrawn 10 periodically for the kinetic monitoring by GC/FID (after 10, 20, 40 and $60 \mathrm{~min}$ for $\mathrm{PPh}_{3}$, every $30 \mathrm{~min}$ until $2 \mathrm{~h}$ and then every hour for the macroligands). For the gas-chromatographic analyses, a precise quantity of anisole (internal standard) was added before dilution with diethyl ether and injection into the ${ }_{15}$ GC/FID. The identification of the reaction components (1-octene, n-nonanal, 2-methyloctanal) was confirmed by GC/MS analysis.

\section{Results and Discussion}

Multiarm star polymers may be accessed by two complementary, convergent (or "arm first") and divergent (or "core 20 first") approaches. In addition to using well defined multifunctional molecular systems as terminating agents (for the arm first approach) or initiators (for the core first approach), it is also possible to use diolefins as cross-linkers yielding microgel cores, with the advantage of simpler operating procedures and a more 25 moderate cost but with the inconvenience of yielding polymers with a variable number of arms. ${ }^{39}$

\section{(a) Convergent polymer synthesis}

Since we have recently synthesized linear P(S-co-SDPP)-Br polymers by ATRP, ${ }^{32}$ we first attempted the synthesis of star 30 polymers from these macroinitiators by the convergent approach and a diolefin cross-linker. Cross-linking indeed took place when using 1,4-divinylbenzene (DVB) to form well defined stars (Scheme 2) as shown by the polymer SEC analysis, but SEC also revealed that a large fraction of the linear macroinitiators was not 35 incorporated into the star product. This phenomenon is well known in the convergent synthesis of star polymers ${ }^{39}$ and is not exclusively caused by the loss of bromide functionality from the linear macroinitiators: the degree of arm chain end functionality revealed by quantitative NMR analysis $(>90 \%)^{32}$ is indeed much 40 larger than the cross-linking yield, at best $41 \%$ (see Experimental Section and Supplemental Figure S1). A number of attempts to optimize the cross-linking yield (use of a DVB-styrene mixture, or EGDMA as cross-linker) did not give better results. A final attempt involved the use of ARGET (Activator ReGenerated by

${ }_{45}$ Electron Transfer) ${ }^{40}$ ATRP conditions to accomplish the crosslinking reaction with $\mathrm{DVB}$, since recent reports have demonstrated the advantage of this approach for the convergent synthesis of star polymers. ${ }^{41}$ Indeed, the cross-linking yield was significantly improved, but it still remained unacceptably low 50 (19\% of free arms remaining, see the SEC trace in Figure S2). Therefore, the convergent synthetic strategy was abandoned and we turned to the divergent synthesis from a preformed microgel core.

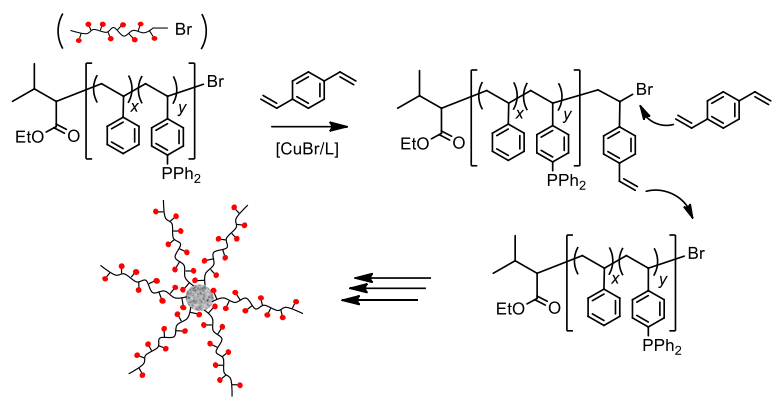

55

Scheme 2

\section{(b) Divergent polymer synthesis}

Among various possible multifunctional initiators, we have focused our attention on Boltorn ${ }^{\mathrm{TM}}$, a commercially available dendridic polyester obtained by polycondensation of 2,260 bis(hydroxymethyl)propionic acid on a central polyol core that offers a large number of hydroxo functionalities. For our purposes we have selected Boltorn ${ }^{\mathrm{TM}} \mathrm{H} 30$ that contains 32 such functional units on average. Therefore, its use as macroinitiator leads to stars with an average of 32 arms. Before divergent arm ${ }_{65}$ growth, Boltorn ${ }^{\mathrm{TM}} \mathrm{H} 30$ was converted to a suitable macroinitiator for ATRP (henceforth abbreviated as $\mathrm{H} 30 \mathrm{Br}$ ) by reaction with 2bromoisobutyroyl bromide, see Scheme 3. The same transformation was previously described for Boltorn ${ }^{\mathrm{TM}} \mathrm{H} 40{ }^{38}$ The completeness of the transformation was confirmed by the ${ }^{1} \mathrm{H}$ ${ }_{70} \mathrm{NMR}$ analysis (Figure S4). The 2-bromoisobutyrate function introduced on $\mathrm{H} 30 \mathrm{Br}$ is a suitable initiator for the ATRP of a variety of monomers, including styrenics. It has been used to functionalize a number of substrates (silicon wafers, cellulose nanocrystals, $\mathrm{PEO}, \ldots$...) for the initiation of styrene 75 polymerization. ${ }^{42-44}$ The macroinitiator $\mathrm{H} 30 \mathrm{Br}$ was then used to grow the copolymer arms as shown in Scheme 3.

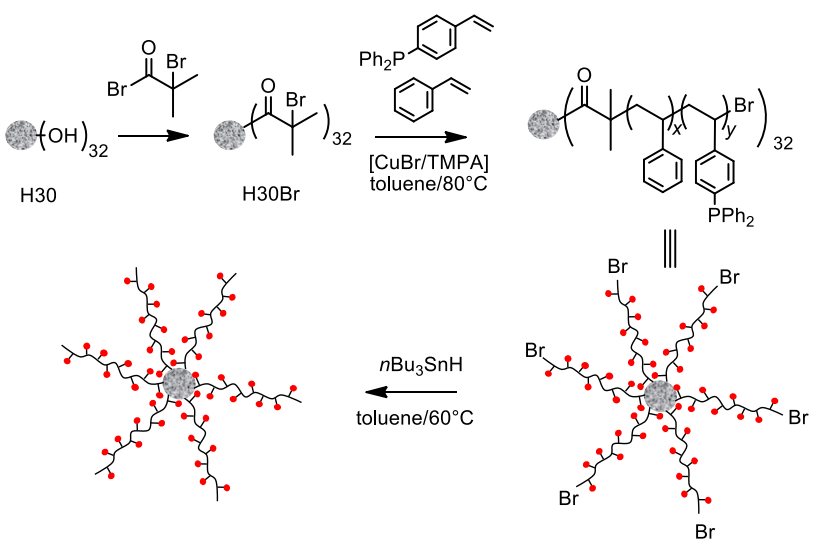

Scheme 3

We selected the $\mathrm{CuBr} / \mathrm{TPMA}$ couple in toluene at $80^{\circ} \mathrm{C}$ as the 80 catalytic system and operating conditions for the subsequent star growth (conditions that were optimized in preliminary experiments on the corresponding star PS homopolymers), which resulted in very slow but well controlled polymerization (the results are collected in Table 1). It is important to point out that, 85 as shown by previously reported controlled experiments, the phosphine groups do not attack the benzylic bromide chain ends under the polymerization conditions. ${ }^{32}$ Three polymers were 
synthesized, two with a feed molar SDPP fraction $f_{\mathrm{SDPP}}=0.17$ and one with $f_{\mathrm{SDPP}}=0.08$. A low SDPP/S fraction in the feed was selected, because our previous work on the linear $\mathrm{P}(\mathrm{S}$-co-SDPP)$\mathrm{Br}$ polymers has shown that good control is achieved only for low

$5 f_{\text {SDPP }}$ values $(\leq 25 \%)$. Given the very slow polymerization and in order to obtain stars of relatively small size, the polymerizations were stopped at low conversion. Use of a more active catalyst such as $\mathrm{CuBr} / \mathrm{Me}_{6} \mathrm{TREN}$ or $\mathrm{CuBr} / \mathrm{PMDETA}$ resulted in gelification even when operating under very dilute conditions. It 10 is worth mentioning that for the synthesis of the linear $\mathrm{P}(\mathrm{S}-\mathrm{co}$ SDPP)-Br copolymers, although the $\mathrm{CuBr}$ /TPMA could insure slower reactions and a better control, the $\mathrm{CuBr} / \mathrm{Me}_{6} \mathrm{TREN}$ system was also able to yield products with well controlled molecular weights and low dispersities.
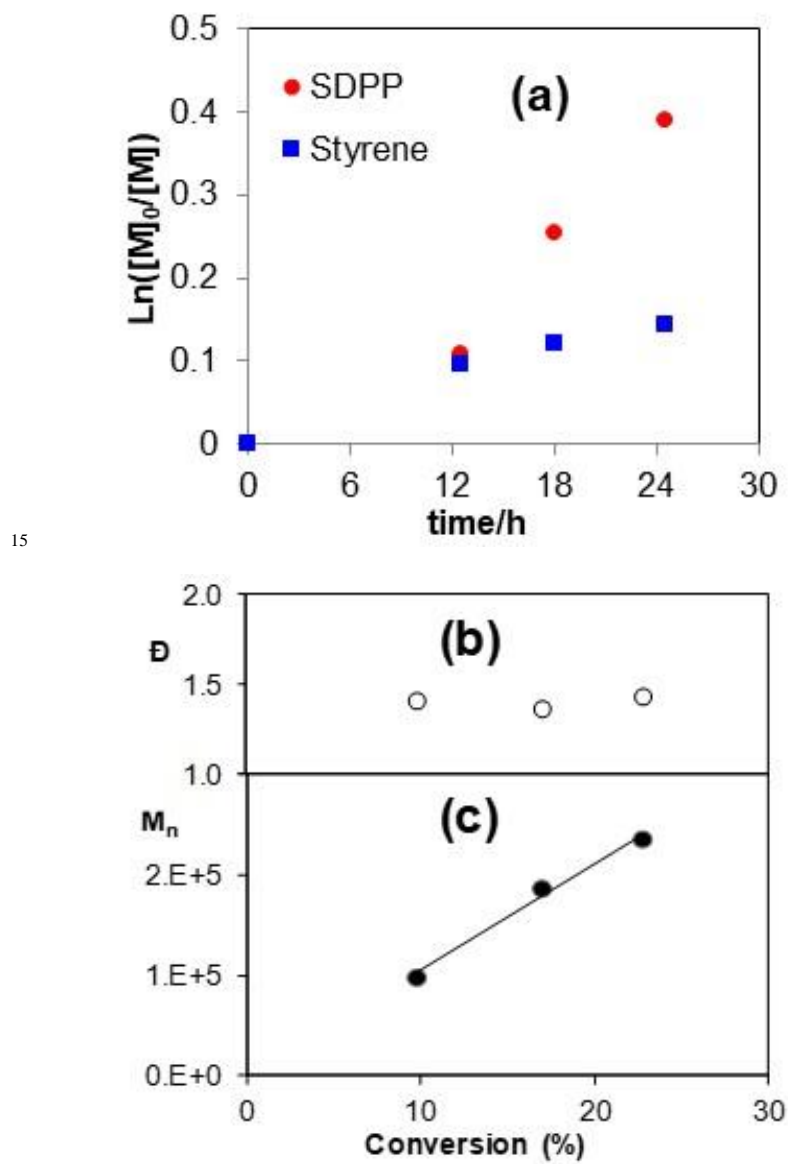

Figure 1. First-order kinetic plot of the monomer conversion (a) and evolution with conversion of $Đ(b)$ and $\mathrm{M}_{\mathrm{n}, \mathrm{SEC}}$ (c) for the star copolymer B-2.

20 Polymers B-1 and B-3 were obtained under the same operating conditions (except on a larger scale and with a slightly longer reaction time for B-3). The similarity of the monomer conversions and polymer parameters for these three polymerizations shows good reproducibility. Polymer B-2 was ${ }_{25}$ obtained with a lower molar SDPP fraction in the feed. The monomer conversions were measured by GC for styrene and by ${ }^{31} \mathrm{P}$ NMR for SDPP (see Experimental Section for details). The ${ }^{31} \mathrm{P}$ NMR indicated no significant oxidation $(<1 \%)$ of the phosphine functionalities. All polymerizations show remarkably 30 good control of the molar mass and low dispersities, especially those with $f_{\text {SDPP }}=0.17$. The measured molecular weights (which were obtained by the complete recovery method given the unavailability of the $\mathrm{dn} / \mathrm{dc}$ value) are always greater than the theoretical values, based on the measured monomer conversion 35 and $\mathrm{H} 30 \mathrm{Br}$ composition (i.e. the known average arm number).

The polymerization leading to B-2 was monitored in terms of kinetics and mass evolution with conversion. The results are shown in Figure 1. The evolution of the monomer conversion with time in the semilogarithmic plot of part (a) shows a 40 relatively good fit to the first order law for both monomers. The faster incorporation of SDPP is in line with the known reactivity ratios for the free radical copolymerization of these two monomers, $(\mathrm{rsDPP}=1.43, \mathrm{rs}=0.52) .{ }^{23}$ Since the reactions were stopped at relatively low conversions, the feed composition drift 45 is limited and therefore the arms should not have a marked compositional gradient. The molecular weight grows linearly with conversion, and the dispersity remains relatively constant around 1.4. These phenomena are characteristic of a controlled system. The SEC traces of these polymers show the uniform 50 progression of the monomodal molecular weight distribution, see Figure S6.

In addition to the SEC characterization, polymer B-1 has also been analyzed by dynamic light scattering, confirming the monomodal distribution and narrow size dispersion (see Figure ${ }_{55} \mathrm{~S} 5$ ), with an average hydrodynamic diameter of $22 \mathrm{~nm}$. The ${ }^{1} \mathrm{H}$ NMR spectrum of the B-1 copolymer, see Figure 2, clearly shows the aliphatic skeleton and aromatic substituent signals, and also the benzylic $\mathrm{CHBr}$ chain end resonance at the characteristic position $(\delta 4.5)$. The small and broad signal in the region between ${ }_{60} \delta 3$ and 4.5 is assigned to the protons of the central Boltorn ${ }^{\mathrm{TM}}$ $\mathrm{H} 30$ core. The large width of this signal is probably caused by the reduced mobility (long correlation time) of this less flexible part of the molecule, even in the good $\mathrm{CD}_{2} \mathrm{Cl}_{2}$ solvent used for the NMR measurement.

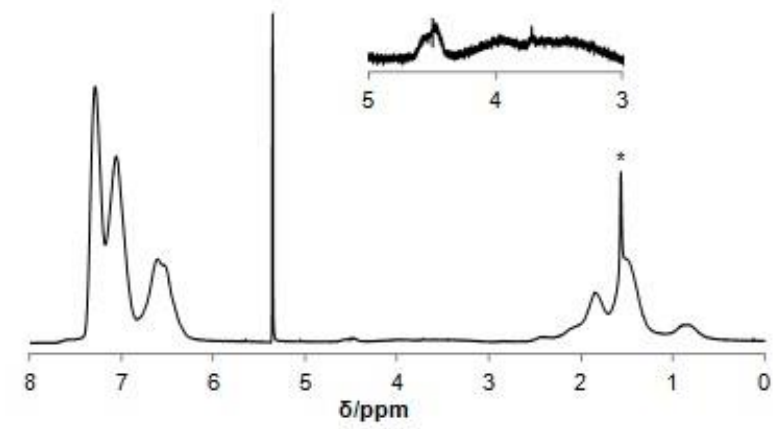

Figure 2. ${ }^{1} \mathrm{H}$ NMR spectrum of polymer B-3 in $\mathrm{CD}_{2} \mathrm{Cl}_{2}$. The sharp starred resonance $(\delta 1.56)$ is due to the solvent water impurity. 
Cite this: DOI: $10.1039 / \mathrm{c0xx} 00000 \mathrm{x}$

Table 1. H30-[P(S-co-SDPP)-Br $]_{32}$ stars synthesized by ATRP. ${ }^{\mathrm{a}}$

\begin{tabular}{|c|c|c|c|c|c|c|c|c|c|c|c|}
\hline Product & $\mathrm{S} / \mathrm{SDPP} / \mathrm{Br}$ & $f_{\mathrm{SDPP}}$ & $\mathrm{t} / \mathrm{h}$ & $\mathrm{S}$ conv $/ \%$ & SDPP conv $/ \%$ & $\mathrm{M}_{\mathrm{n}, \mathrm{SEC}} / \mathrm{g} \cdot \mathrm{mol}^{-1}$ & $\mathrm{M}_{\mathrm{th}} / \mathrm{g} \cdot \mathrm{mol}^{-1}$ & $Ð$ & $\mathrm{dn} / \mathrm{dc}$ & $x^{b}$ & $\mathrm{y}^{\mathrm{b}}$ \\
\hline B-1 & $100: 20: 1$ & 0.17 & 25.5 & 17 & 21 & $3.87 \cdot 10^{5}$ & $1.04 \cdot 10^{5}$ & 1.10 & 0.067 & 17.0 & 4.2 \\
\hline B-2 & 100:10:1 & 0.08 & 24.5 & 13 & 32 & $2.36 \cdot 10^{5}$ & $0.81 \cdot 10^{5}$ & 1.43 & 0.081 & 13.0 & 3.2 \\
\hline B-3 & 100:20:1 & 0.17 & 29.5 & $ـ^{\mathrm{c}}$ & 23 & $4.91 \cdot 10^{5}$ & - & 1.13 & 0.059 & & \\
\hline
\end{tabular}

${ }^{a}$ Conditions: $[\mathrm{H} 30 \mathrm{Br}]=0.01 \mathrm{M}$; $[\mathrm{TPMA}]=0.032 \mathrm{M}, \mathrm{CuBr} / \mathrm{CuBr}_{2} / \mathrm{TPMA}=0.88: 0.12: 1$; solvent $=$ toluene $; \mathrm{T}=80{ }^{\circ} \mathrm{C}$. ${ }^{\mathrm{b}}$ Average number of $\mathrm{S}($ for $\mathrm{x})$ and SDPP (for y) units in each arm (Scheme 3), calculated on the basis of the monomer conversions. ${ }^{\mathrm{c}}$ Not available.

5 In order to establish whether the residual benzylic bromide chain end functionalities interfere with the catalytic application of the macroligands, it was necessary to prepare a dehalogenated version. This was accomplished for polymer B-3, following an established protocol, ${ }^{45}$ by reaction with tributyl tin hydride, as 10 shown in Scheme 3, to give polymer B-3-H. The complete disappearance of the ${ }^{1} \mathrm{H}$ NMR resonance of the terminal $\mathrm{CHBr}$ functions at $\delta 4.5$ (Figure 3) confirms the total elimination of the benzylic bromide chain ends, whereas the ${ }^{31} \mathrm{P}$ NMR spectrum indicates that the polymer-bonded $-\mathrm{PPh}_{2}$ units have been 15 preserved intact (resonance at $\delta-6.2$ ). The SEC analysis shows that a monomodal molecular weight distribution (Figure S7) with parameters close to those of the precursor B-3 polymer $\left(\mathrm{M}_{\mathrm{n}}=\right.$ $\left.4.66 \cdot 10^{5}, Ð=1.35\right)$.

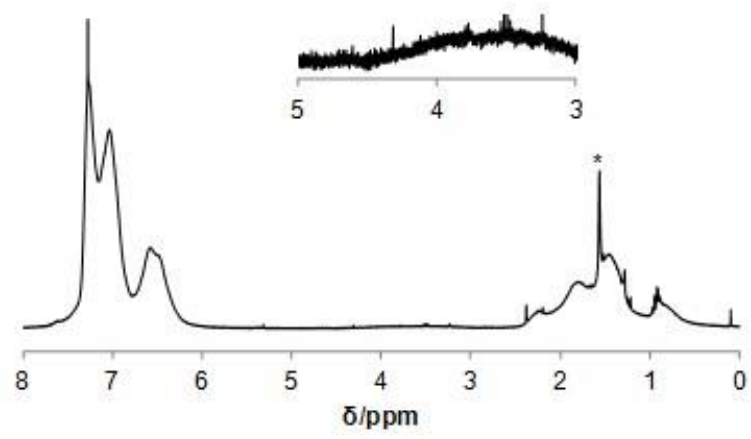

Figure 3. ${ }^{1} \mathrm{H}$ NMR spectrum of polymer B-3-H in $\mathrm{CDCl}_{3}$. The starred resonances is due to the solvent water impurity.

\section{(c) Hydroformylation of 1-octene}

The polymers B-1, B-2, B-3 and B-3-H were then used as macroligands for $\mathrm{Rh}(\mathrm{acac})(\mathrm{CO})_{2}$ in the catalytic hydrofor25 mylation of 1-octene under homogeneous conditions, following the same protocol recently used by us for the same process with the corresponding linear polymers, $\mathrm{P}(\mathrm{S}-\mathrm{co}-\mathrm{SDPP})-\mathrm{Br},{ }^{32}$ and earlier for the catalyst based on $\mathrm{PPh}_{3}{ }^{46}$ The catalytic results are shown in Table 2. From previous work, it is known that the 30 maximum linear/branched (or $1 / \mathrm{b}$ ) ratio is achieved with $\mathrm{P} / \mathrm{Rh}$ ratio of 8 or higher, ${ }^{46}$ whereas the catalytic activity is reduced in the presence of excess phosphine ligand. Indeed, the comparison of the results obtained with a $\mathrm{P} / \mathrm{Rh}$ ratio of 4 and 8 , carried out for the macroligand B-1 (runs 3 and 4) confirms these trends. The
35 comparison with the hydroformylation results in the presence of $\mathrm{PPh}_{3}$ (run 1) or linear copolymer CP-5 (run 2), ${ }^{32}$ shows that increasing ligand complexity (on going from $\mathrm{PPh}_{3}$ to the linear copolymer to the star copolymer) the catalytic activity decreases whereas the $1 / \mathrm{b}$ ratio increases reaching the maximum value of 405.6 for the copolymer B-1 (run 4). Copolymer B-2, containing a lower density of phosphine functionalities, yields a lower $1 / \mathrm{b}$ ratio than copolymer B-1 at similar conversions under identical operating conditions ( $c f$. runs 4 and 5).

Table 2. Homogeneous hydroformylation of 1-octene in toluene solution. ${ }^{a}$

Run Ligand $\mathrm{P} / \mathrm{Rh} \quad \mathrm{t} / \mathrm{h}$ Residual $1 / \mathrm{b}$ Initial rate, $\mathrm{r}_{0} \cdot 10^{4}$

\begin{tabular}{|c|c|c|c|c|c|c|}
\hline & & & \multicolumn{3}{|c|}{ octene $/ \%^{\mathrm{b}}$} & $\left(\mathrm{mol} \mathrm{l}^{-1} \mathrm{~s}^{-1}\right)^{\mathrm{c}}$ \\
\hline 1 & $\mathrm{PPh}_{3}$ & 8 & 0.33 & 7 & 2.8 & 28.5 \\
\hline 2 & $\mathrm{CP}-5^{\mathrm{d}}$ & 8 & 2 & 14 & 3.9 & 7.5 \\
\hline 3 & B-1 & 4 & 4.5 & 25 & 4.5 & 3.1 \\
\hline 4 & B-1 & 8 & 5.5 & 59 & 5.6 & $-\mathrm{e}^{\mathrm{e}}$ \\
\hline 5 & B-2 & 8 & 4.5 & 56 & 4.2 & 2.9 \\
\hline 6 & B-3 & 4 & 4.5 & 28 & 4.0 & 3.8 \\
\hline 7 & B-3-H & 4 & 2.5 & 20 & 4.0 & 5.7 \\
\hline
\end{tabular}

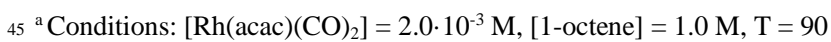
${ }^{\circ} \mathrm{C}, \mathrm{P}_{\text {syngas }}=20$ bar $\left(\mathrm{CO} / \mathrm{H}_{2}=1\right) \cdot{ }^{\mathrm{b}}$ From GC/FID analysis. ${ }^{\mathrm{c}}$ From syngas consumption. ${ }^{\mathrm{d}} \mathrm{CP}-5=\left(\mathrm{CH}_{3}\right)_{2} \mathrm{C}(\mathrm{COOEt}) \cdot\left(\mathrm{SDPP}_{x}-s-\mathrm{S}_{y}\right)-\mathrm{Br}$ with $\mathrm{x}=103$ and $y=26$; data from ref. $32 .{ }^{\mathrm{e}}$ Not available.

A decrease of reaction rate for a polymer supported catalyst is 50 generally explained by a reduced accessibility of the catalytic sites to the olefin, a phenomenon that should be accentuated in bad solvents where the polymer prefers a less expanded conformation and the functionalities are therefore less accessible to the solvent and solute molecules. ${ }^{47}$ The reduced mobility 55 and/or accessibility of the phosphine functions in the more complex star architecture is probably a key factor in the hydroformylation kinetics. The toluene solvent used in these catalytic experiments is actually a relatively good solvent for the PS-type polymer, but the Rh atom may act as intra-chain or inter${ }_{60}$ chain cross-linker, leading to an additional diffusional limitation. This phenomenon should have a greater effect in the star polymers because of the possible inter-arm cross-linking.

From the point of view of selectivity, an improvement of the $1 / \mathrm{b}$ ratio for polymer supported phosphine is well known in the ${ }_{65}$ literature. ${ }^{48-52}$ For instance, the $1 / \mathrm{b}$ ratio for the hydroformylation of propene at $85^{\circ} \mathrm{C}$ approximately doubles from 3 to 6 on going from $\mathrm{PPh}_{3}$ to polypropylene-supported phosphine. ${ }^{50}$ The major effect has been observed, as detailed in our previous contribution, ${ }^{32}$ on going from $\mathrm{PPh}_{3}$ (run 1) to the linear 70 copolymer (run 2). There is, however, a minor but definite further 
increase for the $1 / \mathrm{b}$ ratio upon going from the linear to the star polymer when comparing the results obtained with the same $\mathrm{P} / \mathrm{Rh}$ ratio ( $c f$. run 2 and runs 4 and 5). The polymer B-2 (run 5), containing ca. half the density of $-\mathrm{PPh}_{2}$ functionalities relative to ${ }_{5} \mathrm{~B}-1$, gives a somewhat lower $1 / \mathrm{b}$ ratio. In our previous study on the linear polymers, longer chains were shown to increase the $1 / b$ ratio for equivalent phosphine density. ${ }^{32}$ For the present star polymers, on the other hand, the $1 / b$ ratio decreases when going from the lower MW polymer B-1 to the higher MW polymer B-3 10 ( $c f$. runs 3 and 6).

We have also carried out a catalytic test with the debrominated macroligand $\mathrm{B}-3-\mathrm{H}$ (run 7) under the same conditions as run 6 , namely with a $\mathrm{P} / \mathrm{Rh}$ ratio of 4 . A comparison of the two runs shows that the catalysis is faster with B-3-H than with B-3, 15 whereas the selectivity is identical for the two runs. This observation is at variance with the behavior of the corresponding linear polymers, where the presence of the $\mathrm{Br}$ chain end was found to be totally neutral in terms of both rate and selectivity. ${ }^{32}$ Hence, the terminal $\mathrm{C}-\mathrm{Br}$ functionalities do not appear to 20 chemically inhibit the catalysis. A possible interpretation of this difference is based on the different average conformation for the two polymeric architectures, resulting in a steric hindrance of the $32 \mathrm{Br}$ atoms in the star polymer toward access of the olefin substrate to the catalytic sites, whereas the microstructure of the 25 sites, which control the stereoselecivity, would not be affected. The linear polymers will tend to organize as random coils that will be essentially independent (no entanglements) in dilute solution in a good solvent, as is the case here (1 M solution in toluene). Under these conditions, the presence of only one $\mathrm{Br}$ 30 atom at the chain end will not significantly perturb the substrate access to the catalytic centers distributed in the center of the coil. For the star polymers, on the other hand, each of the 32 arms will propel radially away from the core and therefore place the $\mathrm{Br}$ atoms on or near the polymeric particle surface. Incidentally, this 35 different macromolecular organization of linear and star polymers may also be responsible for the different behavior with respect to the trend of the $1 / b$ ratio with the molecular weight (chain length for the linear polymers or arm length for the star polymers).

Thus, several factors are at play (density of phosphine 40 functionalities, polymer size, architecture, $\mathrm{P} / \mathrm{Rh}$ ratio). Understanding how each one of them independently acts on the $1 / b$ selectivity requires more extensive investigations that are outside the scope of the present preliminary application of our star polymers to catalysis. The important point, however, is that 45 controlled radical polymerization and specifically ATRP under the conditions outlined in the present contribution has the possibility to access polymeric materials where each of these parameters can be individually changed by design. Thus, tailored polymeric macroligands with an optimized structure for each 50 specific application may be developed.

\section{Conclusions}

In this paper, we have taken the atom transfer radical copolymerization of styrene and styryldiphenylphosphine one step further, going from linear copolymers to star polymers with 55 controlled size and phosphine density. The convergent method consisting of cross-linking pre-made chain-end functionalized macroinitiators with a diolefin (divinylbenzene) did not lead to a satisfactory cross-linking yield, although star polymer with controlled size could be obtained. The divergent method starting ${ }_{60}$ from a multifunctional initiator, in the example shown here a hyperbranched polyester of the Boltorn ${ }^{\mathrm{TM}}$ family with ca. 32 external $\mathrm{OH}$ groups, leads to well defined stars with small molecular weight distributions. Their preliminary application to a catalytic process of industrial interest, the hydroformylation of ${ }_{65}$ higher olefins, exemplified in the present case by the model 1 octene substrate, shows the expected performance for a polymersupported phosphine and also demonstrates, in comparison with the previously reported performance of the linear polymers, ${ }^{32}$ that the polymer architecture has an effect on the catalytic 70 performance in addition to polymer size, phosphine density, and $\mathrm{P} / \mathrm{Rh}$ ratio. The present results open several new perspectives in terms of polymer structure optimization, application to other catalytic reactions, catalyst recovery and recycling by ultrafiltration, and development of other polymers with different 75 grafted ligands for an even greater number of catalytic applications.

\section{Acknowledgement}

We are grateful to the Agence Nationale de la Recherche (programme BLANC, project BIPHASNANOCAT, Grant No. 80 ANR-11-BS07-025-01), to the Centre National de la Recherche Scientifique, and to the Institut Universitaire de France, for financial support. AFC thanks the PRES Toulouse for a Ph.D. fellowship. We thank Professor Sergio Castillon (Université Rovira i Virgili, Tarragone) for lending us a generous amount of ${ }_{85}$ Boltorn $^{\mathrm{TM}} \mathrm{H} 30$.

\section{Notes and references}

${ }^{a}$ CNRS, LCC (Laboratoire de Chimie de Coordination), 205 route de Narbonne, BP 44099, F-31077 Toulouse Cedex 4, France CNRS. Fax: +33-561553003; Tel: +33-561333173; E-mail: rinaldo.poli@lcc90 toulouse. $f$ r.

${ }^{b}$ CNRS, LGC (Laboratoire de Génie Chimique), 4 Allée Emile Monso BP 84234, 31030 Toulouse Cedex 4, France

${ }^{c}$ Université de Toulouse, UPS, INPT, F-31077 Toulouse Cedex 4, France

${ }^{d}$ Institut Universitaire de France, 103, bd Saint-Michel, 75005 Paris, 95 France.

$\dagger$ Electronic Supplementary Information (ESI) available: GPC characterization of some of the isolated star polymers. See DOI: $10.1039 / \mathrm{b} 000000 \mathrm{x} /$

1. K. Matyjaszewski, Y. Gnanou and L. Leibler, Macromolecular 100 Engineering: Precise Synthesis, Materials Properties, Applications, Wiley-VCH Verlag GmbH, 2007.

2. C. J. Hawker, A. W. Bosman and E. Harth, Chem. Rev., 2001, 101, 3661-3688.

3. W. A. Braunecker and K. Matyjaszewski, Progr. Polym. Sci., 2007, $105 \quad 32,93-146$.

4. M. Ouchi, T. Terashima and M. Sawamoto, Chem. Rev., 2009, 109, 4963-5050.

5. F. di Lena and K. Matyjaszewski, Progr. Polym. Sci., 2010, 35, 9591021.

110 6. M. Destarac, Macromol. React. Engin., 2010, 4, 165-179.

7. J.-S. Wang and K. Matyjaszewski, J. Am. Chem. Soc., 1995, 117, 5614-5615.

8. M. Kato, M. Kamigaito, M. Sawamoto and T. Higashimura, Macromolecules, 1995, 28, 1721-1723.

115 9. N. E. Leadbeater and M. Marco, Chem. Rev., 2002, 102, 3217-3273.

10. M. Guino and K. K. Hii, Chem. Soc. Rev., 2007, 36, 608-617.

11. J. Manassen, Chim. Ind. (Milan), 1969, 51, 1058-1062. 
12. R. H. Grubbs and L. C. Kroll, J. Am. Chem. Soc., 1971, 93, 30623063.

13. R. H. Grubbs, L. C. Kroll and E. M. Sweet, J. Macromol. Sci. A, 1973, A 7, 1047-1063.

5 14. M. Capka, P. Svoboda, M. Cerny and J. Hetflejs, Tetrahedron Lett., 1971, 4787-4790.

15. G. O. Evans, C. U. Pittman, R. McMillan, R. T. Beach and R. Jones, J. Organomet. Chem., 1974, 67, 295-314.

16. D. C. Bailey and S. H. Langer, Chem. Rev., 1981, 81, 109-148.

10 17. G. Challa, J. Reedijk and P. vanLeeuwen, Polym. Advan. Technol., 1996, 7, 625-633.

18. C. A. McNamara, M. J. Dixon and M. Bradley, Chem. Rev., 2002, 102, 3275-3299.

19. F. Shibahara, K. Nozaki, T. Matsuo and T. Hiyama, Bioorg. Med. Chem. Lett., 2002, 12, 1825-1827.

20. P. W. N. M. van Leeuwen, T. Jongsma and G. Challa, Macromol. Symp., 1994, 80, 241-256.

21. K. G. Allum, R. D. Hancock, I. V. Howell, R. C. Pitkethly and P. J. Robinson, J. Organomet. Chem., 1975, 87, 189-201.

2022 . N. A. Demunck, M. W. Verbruggen and J. J. F. Scholten, J. Mol. Catal., 1981, 10, 313-330.

23. R. Rabinowitz, R. Marcus and J. Pellon, J. Polym. Sci., Polym. Chem., 1964, 2, 1241-1249.

24. M. Kwok, W. Choi, H. S. He and P. H. Toy, J. Org. Chem., 2003, 68, 9831-9834.

25. H. G. Borner and W. Heitz, Macromol. Chem. Phys., 2000, 201, 740746.

26. T. Terashima, M. Kamigaito, K.-Y. Baek, T. Ando and M. Sawamoto, J. Am. Chem. Soc., 2003, 125, 5288-5289.

30 27. T. Terashima, M. Ouchi, T. Ando, M. Kamigaito and M. Sawamoto, J. Polym. Sci., Polym. Chem., 2006, 44, 4966-4980.

28. T. Terashima, M. Ouchi, T. Ando, M. Kamigaito and M. Sawamoto, Macromolecules, 2007, 40, 3581-3588.

29. T. Terashima, M. Ouchi, T. Ando and M. Sawamoto, J. Polym. Sci., $35 \quad A, 2010, \mathbf{4 8}, 373-379$.

30. T. Terashima, M. Ouchi, T. Ando and M. Sawamoto, Polymer Journal, 2011, 43, 770-777.

31. T. Terashima, M. Ouchi, T. Ando and M. Sawamoto, J. Polym. Sci., Polym. Chem., 2011, 49, 1061-1069.

40 32. A. F. Cardozo, E. Manoury, C. Julcour, J.-F. Blanco, H. Delmas, F. Gayet and R. Poli, ChemCatChem, in press.
33. A. Burgath, A. Sunder and H. Frey, Macromol. Chem. Phys., 2000, 201, 782-791.

34. E. Zagar and M. Zigon, Macromolecules, 2002, 35, 9913-9925.

45 35. E. Zagar, M. Zigon and S. Podzimek, Polymer, 2006, 47, 166-175.

36. J. Queffelec, S. G. Gaynor and K. Matyjaszewski, Macromolecules, 2000, 33, 8629-8639.

37. J. Brandrup, E. H. Immergut and E. A. Grulke, eds., Polymer Handbook, 4th edn., John Wiley \& Sons, Inc., Hoboke, NJ, 1999.

50 38. G. Kreutzer, C. Ternat, T. Q. Nguyen, C. J. G. Plummer, J. A. E. Manson, V. Castelletto, I. W. Hamley, F. Sun, S. S. Sheiko, A. Herrmann, L. Ouali, H. Sommer, W. Fieber, M. I. Velazco and H. A. Klok, Macromolecules, 2006, 39, 4507-4516.

39. H. F. Gao and K. Matyjaszewski, Progr. Polym. Sci., 2009, 34, $317-$ 350 .

40. K. Min, H. F. Gao and K. Matyjaszewski, Macromolecules, 2007, 40, 1789-1791.

41. J. Burdynska, H. Y. Cho, L. Mueller and K. Matyjaszewski, Macromolecules, 2010, 43, 9227-9229.

60 42. K. Matyjaszewski, P. J. Miller, N. Shukla, B. Immaraporn, A. Gelman, B. B. Luokala, T. M. Siclovan, G. Kickelbick, T. Vallant, H. Hoffmann and T. Pakula, Macromolecules, 1999, 32, 8716-8724.

43. Z. Y. Li, P. P. Li and J. L. Huang, J. Polym. Sci., Polym. Chem., 2006, 44, 4361-4371.

65 44. G. Morandi, L. Heath and W. Thielemans, Langmuir, 2009, 25, 8280-8286.

45. V. Coessens and K. Matyjaszewski, Macromol. Rapid Comm., 1999, 20, 66-70.

46. R. M. Deshpande, B. M. Bhanage, S. S. Divekar and R. V. 70 Chaudhari, J. Mol. Catal., 1993, 78, L37-L40.

47. M. R. Buchmeiser, Polymeric Materials in Organic Synthesis and Catalysis, Wiley-VCH, Weinheim, 2005.

48. C. U. Pittman and R. M. Hanes, Ann. New York Acad. Sci., 1974, 239, 76-87.

75 49. C. U. Pittman and R. M. Hanes, J. Am. Chem. Soc., 1976, 98, $5402-$ 5405.

50. F. R. Hartley, S. G. Murray and P. N. Nicholson, J. Mol. Catal., 1982, 16, 363-383.

51. P. Kalck, E. L. de Oliveira, R. Queau, B. Peyrille and J. Molinier, J. Organomet. Chem., 1992, 433, C4-C8.

52. N. S. Imyanitov, V. A. Rybakov and S. B. Tupitsyn, Petrol. Chem., 1992, 32, 408-412. 